\title{
Evaluation of a Multilocus Indel DNA Region for the Detection of the Wheat Tan Spot Pathogen Pyrenophora tritici-repentis
}

Pao Theen See, Caroline S. Moffat, Joseph Morina, and Richard P. Oliver, Centre for Crop and Disease Management, Department of Environment and Agriculture, School of Science, Curtin University, Bentley, WA 6102, Australia

\begin{abstract}
See, P. T., Moffat, C. S., Morina, J., and Oliver, R. P. 2016. Evaluation of a multilocus indel DNA region for the detection of the wheat tan spot pathogen Pyrenophora tritici-repentis. Plant Dis. 100:2215-2225.

Tan spot or yellow (leaf) spot disease of wheat (Triticum spp.) is caused by Pyrenophora tritici-repentis, a necrotrophic fungal pathogen that is widespread throughout the main wheat-growing regions in the world. This disease is currently the single most economically important crop disease in Australia. In this study, a real-time quantitative polymerase chain reaction (qPCR) assay was developed as a diagnostic tool to detect the pathogen on wheat foliar tissue. A multicopy locus (PtrMulti) present in the P. tritici-repentis genome was assessed for its suitability as a qPCR probe. The primer pair PtrMulti_F/R that targets the region was evaluated with respect to species specificity and sensitivity. A PtrMulti SYBR qPCR assay was developed and proved to be suitable for the identification and relative quantification of $P$. tritici-repentis with a

detection limit of DNA levels at $<0.1 \mathrm{pg}$. Variation of the PtrMulti copy number between the geographical representatives of $P$. tritici-repentis strains examined was minimal, with the range of 63 to 85 copies per genome. For naturally infected wheat field samples, the incidence of $P$. tritici-repentis DNA on leaves quantified by qPCR varied up to 1,000-fold difference in the concentration, with a higher incidence of DNA occurring on the lower canopy for most of the growth stages examined. At the early growth stages, qPCR assay was able to detect $P$. tritici-repentis DNA on the younger leaves in the absence of visible tan spot lesions. These results demonstrate the potential of PtrMulti probe to be used for early detection and rapid screening of tan spot disease on wheat plants.
\end{abstract}

One of the most devastating and widespread diseases affecting the production of wheat worldwide is tan spot or yellow (leaf) spot, caused by the plant-pathogenic fungus Pyrenophora tritici-repentis. $P$. tritici-repentis is a necrotroph that produces multiple host-specific effectors which cause distinct necrosis and chlorosis on host plants (Lamari et al. 2003). In addition to causing foliar damage on wheat, $P$. tritici-repentis also infects the heads, causing red smudge and affecting grain quality (Fernandez et al. 1998). Tan spot is the single most economically damaging crop pathogen in Australia, with losses exceeding AUD\$200 million per annum (Murray and Brennan 2009).

The incidence of tan spot has been reported in countries of relatively diverse geographic locations such as Australia (Oliver et al. 2008), the United States (Ali et al. 2010; Andrie et al. 2007), Canada (Aboukhaddour et al. 2013), South America (Gamba et al. 2012), and the Middle East (Lamari et al. 2003). P. tritici-repentis isolates are classified into eight races based on their virulence on specific differential wheat lines (Ali and Francl 2002; Lamari et al. 2003, 1995). However, the classical race structure of $P$. tritici-repentis has been challenged with the emergence of studies that have identified isolates that do not conform to any of the eight races (Ali et al. 2010; Andrie et al. 2007), suggestive of a broader range of pathotypes and the presence of as yet uncharacterized effectors. The economic importance of wheat and the global distribution of tan spot disease, in conjunction with the complex race structure of the pathogen, highlight the importance of developing detection tools to study the epidemiology and biology of $P$. tritici-repentis.

Detection of $P$. tritici-repentis using the conventional cultured-based diagnosis is time consuming and prone to misdiagnosis if diseased leaf samples are contaminated with saprophytes. Imaging techniques such as chlorophyll fluorescence imaging have been evaluated for the detection

Corresponding author: P. T. See; E-mail: PaoTheen.See@curtin.edu.au

*The $\boldsymbol{e}$-Xtra logo stands for "electronic extra" and indicates that one supplementary figure is published online.

Accepted for publication 28 June 2016.

http://dx.doi.org/10.1094/PDIS-03-16-0262-RE

(C) 2016 The American Phytopathological Society of tan spot (Kenny et al. 2011). Using fluorescence data, photosynthetic activity was correlated to the resistance or susceptibility of the host, and infection was detected as early as 3 days postinfection (dpi). Although imaging technology offers promises in improving the assessment of plant disease phenotypes, imaging approaches are not an effective diagnostic tool in distinguishing diseases (Mutka and Bart 2015). Since the discovery of polymerase chain reaction (PCR), faster and more robust detection methods employing real-time quantitative PCR (qPCR) have been adopted that combine specificity at taxonomic levels and enable quantification of species DNA in complex matrices such as soil and in planta (Amatulli et al. 2012; Jiménez-Fernández et al. 2011; Sanzani et al. 2014). For in planta analysis, nuclear ribosomal DNA (rDNA) has been extensively used in qualitative PCR and qPCR assays for the detection of fungi and bacteria (Arif et al. 2014; Dorn-In et al. 2015). In fungi, the internal transcribed spacer (ITS) regions are commonly used as probes for taxonomic and phylogenetic identification (Monard et al. 2013; O'Brien et al. 2005). In addition to the general ITS primers that were developed in the early 1990s (Gardes and Bruns 1993; White et al. 1990), numerous primers targeting the ITS region have been utilized as DNA probes in fungi (Ihrmark et al. 2012; Martin and Rygiewicz 2005). The broad application of ITS regions is due to their highly conserved repetitive rDNA sequences that occur as a process of concerted evolution (Elder and Turner 1995), and the extensive depository of ITS sequences available in the public sequence database, providing a large reference resource for species identification (Begerow et al. 2010). ITS regions have a high probability of identifying a broad taxonomic group of fungi (most notably, species of Ascomycota and Basidiomycota) and are regarded as a universal DNA barcode (Schoch et al. 2012). In comparison with microsatellite loci, the copy number of ribosomal small subunit DNA loci has been shown to be 1,000-fold higher compared with simplesequence repeat (Dreaden et al. 2014), distinguishing rDNA as a popular detection probe.

Although nuclear rDNA sequences are widely used as universal barcodes for fungi, there are limitations in terms of their applications. Tandem repeats of rDNA that vary significantly within species have been reported in various fungal species such as Aspergillus fumigatus (Herrera et al. 2009), Coccidioides spp. (Johnson et al. 2015), and Batrachochytrium dendrobatidis (Longo et al. 2013). Although the multicopy nature of the rDNA region increases the detection sensitivity of small DNA quantity, such variation in the probe copy number is strain dependent 
and, thus, may lead to over- or underestimation of fungal load in quantitative and comparative studies. Furthermore, although some degree of intragenomic variations are observed (Lindner and Banik 2011; Lindner et al. 2013), the ITS sequences are insufficiently variable, which makes it less desirable when species-level resolution is required. In P. tritici-repentis, sequence analysis of 20 geographically diverse strains revealed only 2 strains with sequence variation of a single base pair (Lepoint et al. 2010).

Comparative genomic analysis of the $P$. tritici-repentis effector ToxA genetic locus with the colinear locus in Parastagonospora nodorum (a closely related species from the pleosporalean taxa) revealed an indel region located upstream of the transcription site (Friesen et al. 2006). It has been postulated that, in the 1940s, a horizontal gene transfer event occurred in which the ToxA gene was transferred interspecifically from $P$. nodorum to $P$. tritici-repentis, thus contributing to the success of $P$. tritici-repentis as a major pathogen in wheat. The 11-kb sequence which contains the ToxA loci is relatively conserved in both species, with a similarity of 80 to $100 \%$ varying at the peripheral and central region. However, a region of 197 bp located upstream from the ToxA gene is only present in the $P$. tritici-repentis genomic sequence and absent in $P$. nodorum. It was present as multiple copies in the genome sequence (Manning et al. 2013), indicating that it existed in the P. tritici-repentis genome prior to ToxA invasion. This unique asymmetric region adjacent to the ToxA gene in $P$. tritici-repentis genome, designated as PtrMulti, allows the development of a species-specific PCR assay for identification and quantification of this pathogen. A preliminary assay using the PtrMulti_F and PtrMulti_R primer pair that targets the indel region was successfully used to differentiate spontaneous yellowing of 'Mace' wheat from tan spot disease (Moffat et al. 2015).

In this study, the PtrMulti loci region is evaluated for suitability as a qualitative PCR and qPCR probe, and for application as a diagnostic tool in the detection and quantification of $P$. tritici-repentis in wheat field samples. The advantages and limitations of the PtrMulti as a qPCR diagnostic tool are discussed.

\section{Materials and Methods}

Plant and fungal materials. Seed of the Australian wheat 'Yitpi' (Triticum aestivum L.), rated as susceptible to very susceptible (DAFWA 2015), were sown in two independent $2 \times 1 \mathrm{~m}$ plots in June 2013. The plots were overlaid with wheat stubble as the primary source of inoculum collected from a field with high tan spot disease pressure. Whole wheat plant samples were collected at a monthly intervals (July, August, September, and October) at the growth stages of stem elongation (GS30), flag leaf emergence or booting (GS39 to GS40), flowering (GS60), and grain fill period (GS70). To overcome sample variability resulting from natural infection, eight plants were randomly collected from the plot at each time point. Tan spot disease was visually assessed and leaves photographed. Plant material was stored at $-80^{\circ} \mathrm{C}$ prior to DNA extraction.

To represent the genetic diversity of the $P$. tritici-repentis population, pure isolates from diverse geographic locations in Australia as well as two American isolates were used in the primer specificity assay (Table 1). Race designation of the Australian P. tritici-repentis isolates was determined by PCR amplification of DNA using primers ToxAscreeningF/R and TB10f/TB12r to detect the presence or absence of ToxA and ToxB genes, respectively (Antoni et al. 2010), as well as visual assessment of disease phenotype on wheat differential lines (Lamari et al. 2003). The race of isolates DW5 and DW7 was based on published data (Friesen and Faris 2004). Pure fungal cultures of Alternaria tritici, A. infectoria,

Table 1. Pyrenophora tritici-repentis isolates used in this study

\begin{tabular}{lllc}
\hline Isolate & Year & \multicolumn{1}{c}{ Geographic origin } & Race \\
\hline M4 & 2009 & Western Australia, Australia & 1 \\
WAC11137 & 2001 & Western Australia, Australia & 1 \\
239 & 2003 & Victoria, Australia & 1 \\
134 & 2006 & Queensland, Australia & 1 \\
WAC5216 & 1987 & New South Wales, Australia & 1 \\
DW5 & 1998 & North Dakota, United States & 5 \\
DW7 & 1998 & North Dakota, United States & 5 \\
\hline
\end{tabular}

and Fusarium lateritium were obtained from the field and the fungal species were confirmed by sequencing the ITS regions, as previously described by Moffat et al. (2015).

DNA extraction of plant and fungal materials. For individual wheat plants, each leaf was excised, freeze-dried, and ground into a fine powder in liquid nitrogen using a mortar and pestle. A fine balance was used to measure out $10 \mathrm{mg}$ of ground leaf material, which was placed in a $1.5-\mathrm{ml}$ microtube. Plant DNA was extracted using the Biosprint 15 DNA kit (Qiagen) according to the manufacturer's protocol.

Fungal mycelia of $P$. tritici-repentis, $P$. teres $f$. maculata, $P$. teres f. teres, A. tritici, A. infectoria, and F. lateritium were grown on V8 potato dextrose agar media plates and harvested after 10 days (Moffat et al. 2014). DNA was extracted from the mycelium using Biosprint 15 DNA kit (Qiagen) according to the manufacturer's protocol.

DNA concentrations were determined using a NanoDrop 2000 UV-Vis spectrophotometer (Thermo Scientific). DNA from pure culture of P. nodorum, Ascochyta rabiei, A. lentil, and Botrytis cinerea were kindly provided by other researchers.

Sequence analysis and primer design. A 1.4-kb region containing the ToxA gene from $P$. tritici-repentis was identified in the genomic scaffold_00011 (isolate M4) and aligned to the orthologous DNA sequence of $P$. nodorum. The sequence of $P$. nodorum containing the ToxA locus (SNOG_16571) and the flanking regions was downloaded from Broad Institute of MIT (http://www.broadinstitute.org). Nuclear ribosomal RNA sequences of genus Pyrenophora were retrieved from fungal barcoding database (http://www.fungalbarcoding.org) (Schoch et al. 2012) and the $P$. tritici-repentis rDNA sequences used in this study were obtained from $P$. tritici-repentis genome database (http://www.broadinstitute.org).

To determine the repeat regions of PtrMulti, the 235-bp region containing the PtrMulti sequence was identified in the genomic scaffolds of isolate M4. For the comparison of PtrMulti sequences in P. teres species, the region was subjected to blast searches of $P$. teres $\mathrm{f}$. maculata and $P$. teres $\mathrm{f}$. teres genomes. Sequence analysis and multiple sequence alignment were constructed using Geneious version 6.1.8. Primers were designed using Primer3.

Primer specificity. Conventional PCR was used to evaluate the specificity of PtrMulti_F (5' GTAAGCCCGAGCAGAAGGAC 3') and PtrMulti_R (5' CCATAGGCGACCGAGTAGAG 3') via amplifications with fungal strains, including $P$. tritici-repentis, $P$. nodorum, Alternaria spp., Ascochyta spp., B. cinerea, and F. lateritium. The specificity of the single-copy locus PtrUnique region has been described previously (Antoni et al. 2010) and was not tested in this study. Each $20 \mu \mathrm{l}$ of PCR contained $1 \times$ MyTaq buffer, $250 \mathrm{nM}$ each forward and reverse primer, $1 \mathrm{U}$ of MyTaq DNA polymerase (Bioline), and $50 \mathrm{ng}$ of DNA template. Amplification was performed with the following cycling conditions: $2 \mathrm{~min}$ of denaturation, 35 cycles of $30 \mathrm{~s}$ of denaturation at $95^{\circ} \mathrm{C}$ and $30 \mathrm{~s}$ of annealing at $59^{\circ} \mathrm{C}$, and $1 \mathrm{~min}$ of extension at $72^{\circ} \mathrm{C}$. Primer pair NL5mun (Egger 1995) and NLC2 (Martin and Rygiewicz 2005) that target the large subunit (LSU) of the ribosomal operon was used as a PCR amplification control.

For the barley pathogens $P$. teres f. maculata and P.teres f.teres, the primer specificity of PtrMulti_F/R, Ptt_F (5' ATAAGCCCG AGCAGAAGAAC $\left.3^{\prime}\right)$ and Ptt_R (5'CCATTAGAAAACCGAGTA GAG 3') was tested on the DNA of two different strains of each $P$. teres form using DyNAzyme Ext Taq DNA polymerase (Thermo Fisher Scientific). Each $20 \mu \mathrm{l}$ of PCR contained 1× DyNAzyme Ext Taq buffer, $250 \mathrm{nM}$ each forward and reverse primer, $1 \mathrm{U}$ of DyNAzyme Ext Taq DNA polymerase, and 50 ng of DNA template. Amplification was carried out using the following cycling conditions: 2 min of denaturation, 35 cycles of $30 \mathrm{~s}$ of denaturation at $95^{\circ} \mathrm{C}$ and $30 \mathrm{~s}$ of annealing at $65^{\circ} \mathrm{C}$, and $30 \mathrm{~s}$ of extension at $72^{\circ} \mathrm{C}$. PCR products were electrophoresed on $1.5 \%$ agarose gel prestained with SYBR safe (Life Technologies).

Determination of PtrMulti copy number. Copy number determination of PtrMulti was performed using the qPCR standard curve method, as previously described by Whelan et al. (2003). Briefly, primer pairs PtrMulti_F/R plus Act1F4 (5'CGAGACCTTCAACGCTC CCGC 3') and Act1R4 (5' GCGTGGGGAAGAGCGAAACCC 3') were used to amplify $150 \mathrm{bp}$ of the PtrMulti region and the singlecopy actin gene (Act1), respectively, in $20 \mu$ l of PCR containing 
$1 \times$ MyTaq buffer, $250 \mathrm{nM}$ each forward and reverse primer, $1 \mathrm{U}$ of MyTaq DNA polymerase, and $50 \mathrm{ng}$ of M4 DNA. Amplification was performed with the following cycling conditions: 2 min of denaturation, 35 cycles of $30 \mathrm{~s}$ of denaturation at $95^{\circ} \mathrm{C}$ and $30 \mathrm{~s}$ of annealing at $55^{\circ} \mathrm{C}$, and $1 \mathrm{~min}$ of extension at $72^{\circ} \mathrm{C}$. PCR products were analyzed in gel electrophoresis and gel purified using the QIAquick Gel Extraction Kit (Qiagen) according to the manufacturer's instruction. Purified PCR amplicons were quantified using a NanoDrop 2000 UV-Vis spectrophotometer (Thermo Scientific). Based on the DNA concentration and sequence length, the copy numbers of the PtrMulti and Actl fragments were calculated using the following formula (Whelan et al. 2003): copy number = $\left[6.02 \times 10^{23}(\mathrm{copy} / \mathrm{mol}) \times\right.$ DNA concentration $\left.(\mathrm{g})\right] /[\mathrm{DNA}$ length (bp) $\times 660(\mathrm{~g} / \mathrm{mol} / \mathrm{bp})]$.

A 10 -fold serial dilution of $10^{1}$ to $10^{8}$ copies for each fragment was then prepared as template DNA for real-time PCR. To generate the standard curves, real-time qPCR detection was carried out in a $20-\mu 1$ reaction consisting of template DNA, $10 \mu \mathrm{l}$ of QuantiTect SYBR Green PCR mix (Qiagen), and $300 \mathrm{nM}$ each forward and reverse primer. Real-time PCR was performed in a CFX96 Real-time PCR Detection System (Bio-Rad) with the following cycling conditions: $95^{\circ} \mathrm{C}$ for $15 \mathrm{~min}$ of denaturation, 35 cycles of $15 \mathrm{~s}$ of denaturation at $94^{\circ} \mathrm{C}$ and $30 \mathrm{~s}$ of annealing at $65^{\circ} \mathrm{C}$, and $30 \mathrm{~s}$ of extension at $72^{\circ} \mathrm{C}$, with the acquisition of fluorescence data during each step of annealing cycle. All the reactions were performed with three replicates. The standard curves were generated by plotting the threshold cycle $(\mathrm{Ct})$ value against the log copy number. The PCR efficiencies of the reactions were calculated from the standard curve slope using the following equation: $E=10^{(-1 / \text { slope })}-1$. To determine the genome copy number of PtrMulti, qPCR $(20 \mu \mathrm{l})$ assays were prepared as described above, except that the DNA template consisted of $50 \mathrm{ng}$ of genomic DNA of $P$. tritici-repentis isolates (Table 1). Absolute quantification was then performed using the standard curves to calculate the copy number of PtrMulti and Actl corresponding to the $\mathrm{Ct}$ values obtained from the real-time PCR analysis of the genomic DNA. The PtrMulti copy number was then normalized to Actl copy number. Because Actl is single copy, the copy numbers obtained for PtrMulti represent the genome copy number.

Sensitivity of PtrMulti primers. To assess the performance of the multiloci primer pair PtrMulti_F/R, a comparison between PtrMulti_F/R and the single-locus primer pair PtrUniqueF1 (5' CCGGCTGATATTC CCCCACCG 3') and PtrUniqueR1 (5' GGCCTCCGCTGGCGAGTA AA $3^{\prime}$ ) was assessed in a real-time PCR assay with a 10-fold serial dilution of $P$. tritici-repentis DNA (from the range of 0.001 to $100 \mathrm{ng}$ ). To evaluate the performance of these primer pairs in infected wheat materials, a series of diluted wheat DNA $(1,10$, and $100 \mathrm{ng})$ was spiked with $P$. tritici-repentis DNA at concentration of $0.1,0.01$, and $0.001 \mathrm{ng}$ to simulate a DNA mixed matrix of pathogen-host DNA at ratios of 1:10, 1:100, and 1:1,000. The qPCR $(20 \mu \mathrm{l})$ consisted of template DNA, $10 \mu l$ of QuantiTect SYBR Green PCR mix (Qiagen), and $300 \mathrm{nM}$ forward and reverse primers. Real-time PCR was performed as described above. At the end of the qPCR, a default dissociation curve was performed for melt curve analysis. Standard curves were generated by plotting the $\mathrm{Ct}$ values against the log concentration of the 10 -fold serial diluted DNA. Concentrations of $P$. tritici-repentis DNA were then inferred from the standard curves using the absolute quantification method. All the reactions were performed with three replicates.

Detection of $P$. tritici-repentis DNA in planta using PtrMulti qPCR assay. qPCR was performed using primer PtrMulti_F and PtrMulti_R to detect relative amounts of $P$. tritici-repentis DNA in the leaf material. The components for the qPCR were as follows: $50 \mathrm{ng}$ of template DNA, $10 \mu \mathrm{l}$ of QuantiTect SYBR Green PCR mix (Qiagen), and $300 \mathrm{nM}$ PtrMulti_F and PtrMulti_R. A standard dilution series of $P$. tritici-repentis DNA at 100, 50,10,1,0.1, and $0.01 \mathrm{ng}$ was included in the $\mathrm{qPCR}$ analysis to generate the standard curve for absolute quantification. Real-time PCR was performed as described above. For each time point, at minimum, seven biological repeats were analyzed to overcome biological variation. Standard

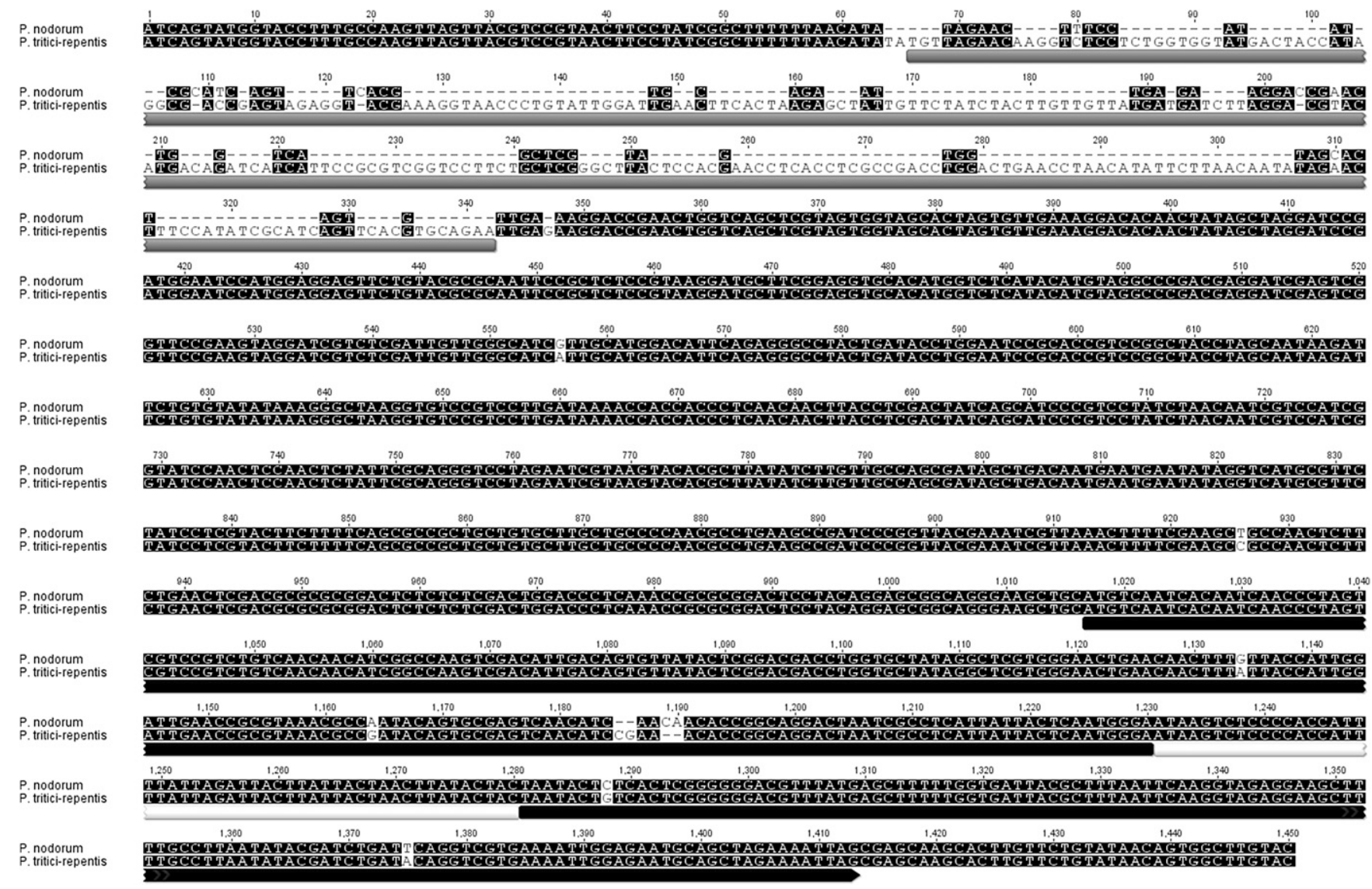

Fig. 1. Nucleotide sequence alignment of the Pyrenophora tritici-repentis and Parastagonospora nodorum 1.4-kb genomic region containing the ToxA locus. The indel region and the ToxA gene coding sequence are indicated by gray and black annotations, respectively. The intron region of the ToxA is annotated in white. Identical nucleotides are shaded. 
curves were generated by plotting the $\mathrm{Ct}$ values against the log concentration of DNA. The resulting data were assessed statistically using one-way factorial analysis of variance. Mean comparisons were performed using an all-pairs Tukey's test. All statistically analyses were performed using JMP version 10 software.

Photosynthetic pigment measurements. Freeze-dried plant materials were ground to fine powder using a mortar and pestle with liquid nitrogen. A homogenized leaf sample $(10 \mathrm{mg})$ was transferred to a microtube and extracted with $120 \mu \mathrm{l}$ of $80 \%$ ( $\mathrm{vol} / \mathrm{vol})$ acetone. The tubes were wrapped in foil and mixed for $30 \mathrm{~min}$ on a rocking platform. Samples were then centrifuged at $3,000 \mathrm{rpm}$ for $15 \mathrm{~min}$ at $4^{\circ} \mathrm{C}$. The crude acetone extract $(50 \mu \mathrm{l})$ was then transferred to a flatbottomed 96-well plate. Chlorophylls ( $a$ and $b$ ) and carotenoid were measured spectrophotometrically at wavelengths of 663, 646, and $470 \mathrm{~nm}$ using a Synergy HT multimode microplate reader (BioTek).
The concentrations of the pigments chlorophyll $a$, chlorophyll $b$, and carotenoid were calculated according to Lichtenthaler and Wellburn (1983).

\section{Results}

Sequence analysis and primer design of PtrMulti region. Alignment of the 1.4-kb locus region of the ToxA gene from $P$. triticirepentis and $P$. nodorum showed the indel polymorphic region of 282 bp located $669 \mathrm{bp}$ upstream from the gene (Fig. 1). In order to evaluate the indel sequence within the $P$. tritici-repentis genome, this region was identified in the genome of isolate M4. A DNA region of $235 \mathrm{bp}$ containing the indel sequence not only was found upstream from the ToxA promoter but also was conserved within the genome, as shown in the alignment in Figure 2. Initially, two sets of primer pairs $(\mathrm{F} 1 / \mathrm{R} 1$ and $\mathrm{F} 2 / \mathrm{R} 2)$ that generate a short PCR fragment

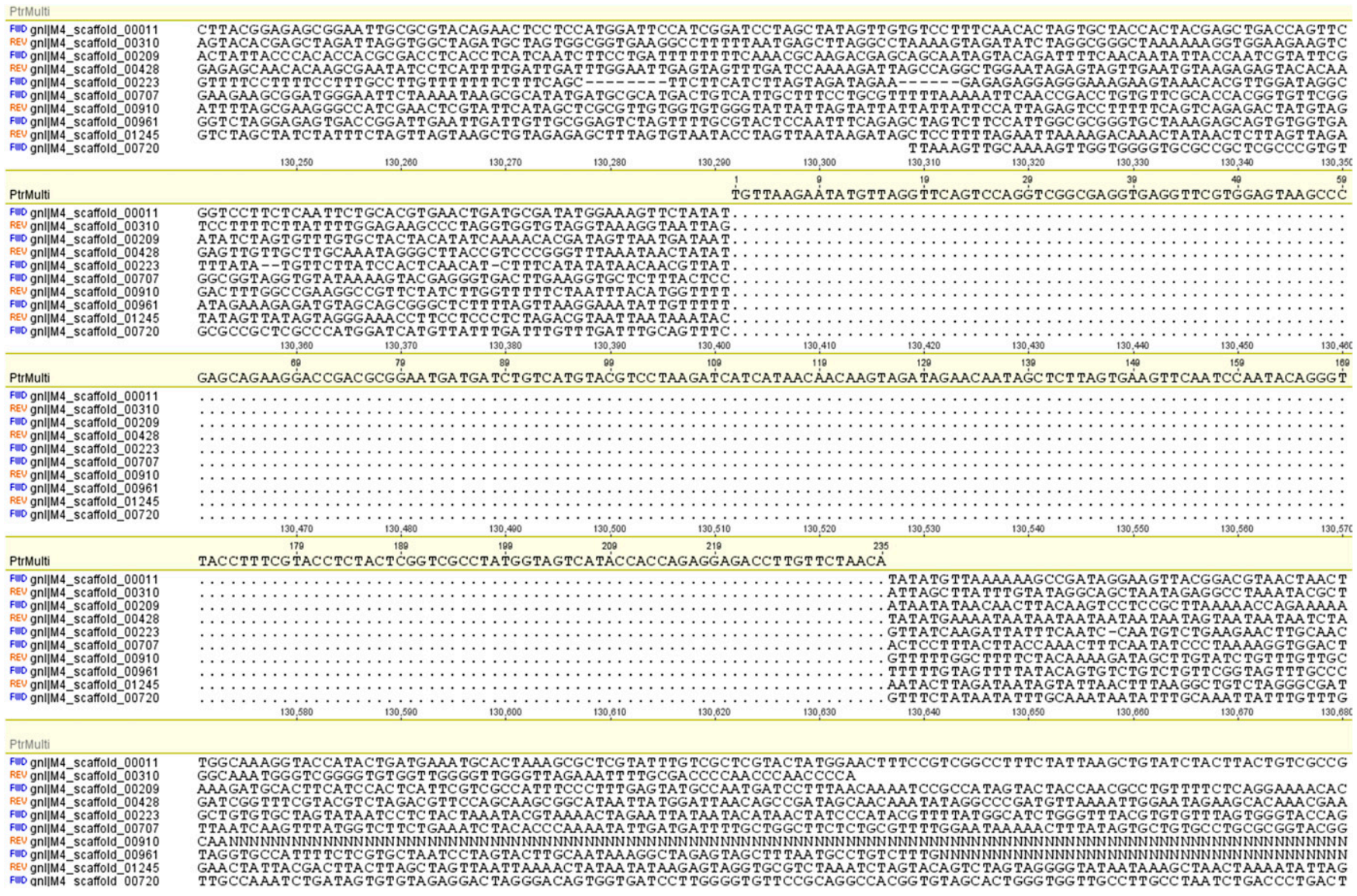

Fig. 2. Multiple sequence alignment of Pyrenophora tritici-repentis contigs containing the 235 -bp multilocus region. The consensus sequence is annotated as dotted lines.

A

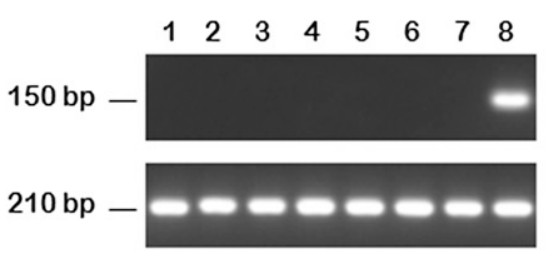

B

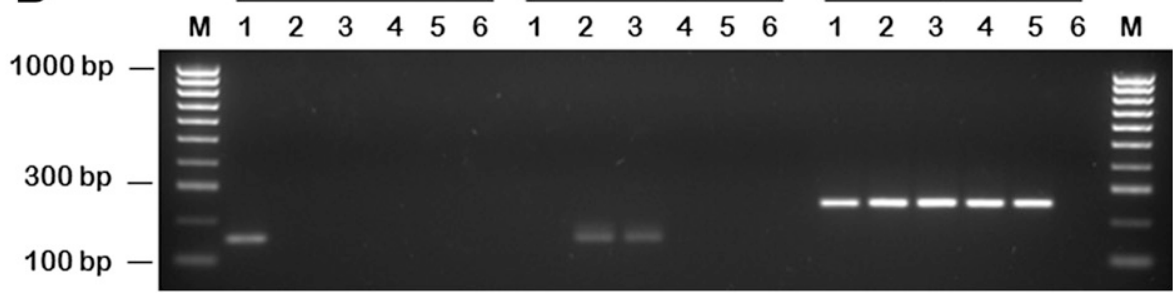

Fig. 3. A, Agarose gel analysis of polymerase chain reaction (PCR) amplification using the species-specific primer pair PtrMulti_F/R (top panel). Lane 1, Fusarium lateritium; lane 2, Alternaria infectoria; lane 3, A. triticina; lane 4, Ascochyta rabiei; lane 5, A. lenti;; lane 6, P. nodorum; lane 7, Botrytis cinerea; and lane 8, P. tritici-repentis. The internal transcribed spacer (ITS) primers ITSmun and NLC5 were used for positive control amplification (bottom panel). B, Specificity of PtrMulti_F/R and Ptt_F/R primer pairs tested against $P$. triticirepentis and $P$. teres DNA using conventional PCR. Lane M, DNA marker $=100 \mathrm{bp}$ (Bioline); lane 1, $P$. tritici-repentis; lane 2, $P$. teres f. teres 1; lane 3, $P$. teres f. teres 2; lane 4, $P$. teres f. maculata 1; lane 5, P. teres f. maculate 2; lane 6, negative control. ITS primers ITSmun and NLC5 were used for positive control amplification. Molecular weights of the respective amplicons are indicated on the left of the figure. 
(150 bp) suitable for qPCR were designed targeting the 235-bp multilocus region. Primer specificity was tested on various plant fungal pathogens that included closely related Pleosporales species and saprobes that are commonly found in wheat. From the two sets of primer pairs, F2/R2 generated the expected amplicon of $150 \mathrm{bp}$ from $P$. tritici-repentis DNA, whereas primer set F1/R1 had unspecific amplification bands on most of the DNA tested (data not shown). Thereafter, primer pair F2/R2, which was named PtrMulti_F and PtrMulti_R, was used for the subsequent PCR assays. PtrMulti_F/R was species specific and no amplification was observed for the DNA of other pathogens examined (Fig. 3A). A blast search of the 235-bp region against the National Center for Biotechnology Information GenBank database revealed no significant homology to other fungal species of Pyrenophora except for the $P$. teres f. teres genome, which revealed a region that has a $62 \%$ identity to the PtrMulti region (Fig. 4). To examine these regions of homology between $P$. tritici-repentis and $P$. teres, two sets of distinct primers (PtrMulti_F/R and Ptt_F/R) were designed and tested for their specificity against $P$. tritici-repentis and $P$. teres isolates using conventional PCR. Primer optimization was essential in order to obtain specific amplicons that distinguish $P$. tritici-repentis and $P$. teres f. teres due to their close homology. Upon optimization of the PCR, a single amplification size of $150 \mathrm{bp}$ that corresponds to the genomic DNA sequences of $P$. tritici-repentis and $P$. teres $\mathrm{f}$. teres using primer pairs PtrMulti_F/R and Ptt_F/R, respectively, was achieved (Fig. 3B). The conventional PCR assay using primer pair Ptt_F/R showed an amplicon of $150 \mathrm{bp}$ in size for the two P. teres f. teres DNA isolates tested in the assay and, as expected, no amplification was observed for $P$. tritici-repentis DNA. However, DNA from the two P. teres f. maculata isolates also yielded no amplification, indicating the presence of the PtrMulti-like region in P. teres f. teres but not in P. teres f. maculata.

Detection of PtrMulti copy number in $P$. tritici-repentis. The copy number of the PtrMulti region was determined by normalizing the target region to the actin Act1 gene, which was confirmed by whole-genome sequence to be a suitable single-copy reference gene (Ellwood et al. 2012). To perform the normalization strategy, first, a 10 -fold serial dilution of the DNA amplicon ranging from $10^{1}$ to $10^{8}$ copies was employed to generate the standard curves for PtrMulti and Actl, respectively. The standard curves of the log DNA versus Ct for both PtrMulti and Actl were near linear (coefficient correlation value $R^{2}$ of 0.9989 and 0.9969 , respectively), with slope values of $-3.5455 x$ (PtrMulti) and -3.5217x (Act1). Calculated amplification efficiencies were comparable between PtrMulti and Act1 at 91.4 and $92.3 \%$, respectively. The copy numbers of PtrMulti and the Actl gene (single-copy control) of the local and two overseas $P$. tritici-repentis isolates listed in Table 1 were calculated using the standard curves obtained. Because Actl is single copy, the relative copy number of PtrMulti to actin represents the genome copy number. The qPCR data showed that the isolates tested have near equal copy number of PtrMulti, ranging from $63 \pm 20$ to $85 \pm 22$ copies per genome (Fig. 5).

Specificity and sensitivity of PtrMulti qPCR. In order to use PtrMulti as an in planta probe, the amplification specificity and sensitivity of PtrMulti were assessed in a simulated mixed matrix of fungal and plant DNA. The PtrMulti_F/R primers were tested by

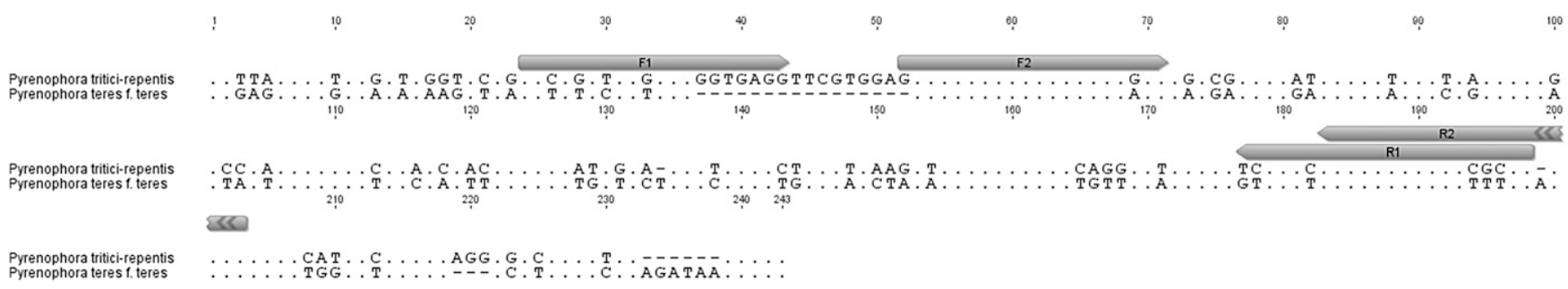

Fig. 4. Nucleotide sequence alignment of PtrMulti and the homologous locus of Pyrenophora teres $\mathrm{f}$. teres. The schematic diagram shows the positions of the two primer pairs tested for polymerase chain reaction species specificity. Primer binding sites and directions are annotated above their sequence positions. Variable nucleotides are shown in the sequence and consensus sequences are shown as dots. Gaps in the aligned sequences are shown as dashes.

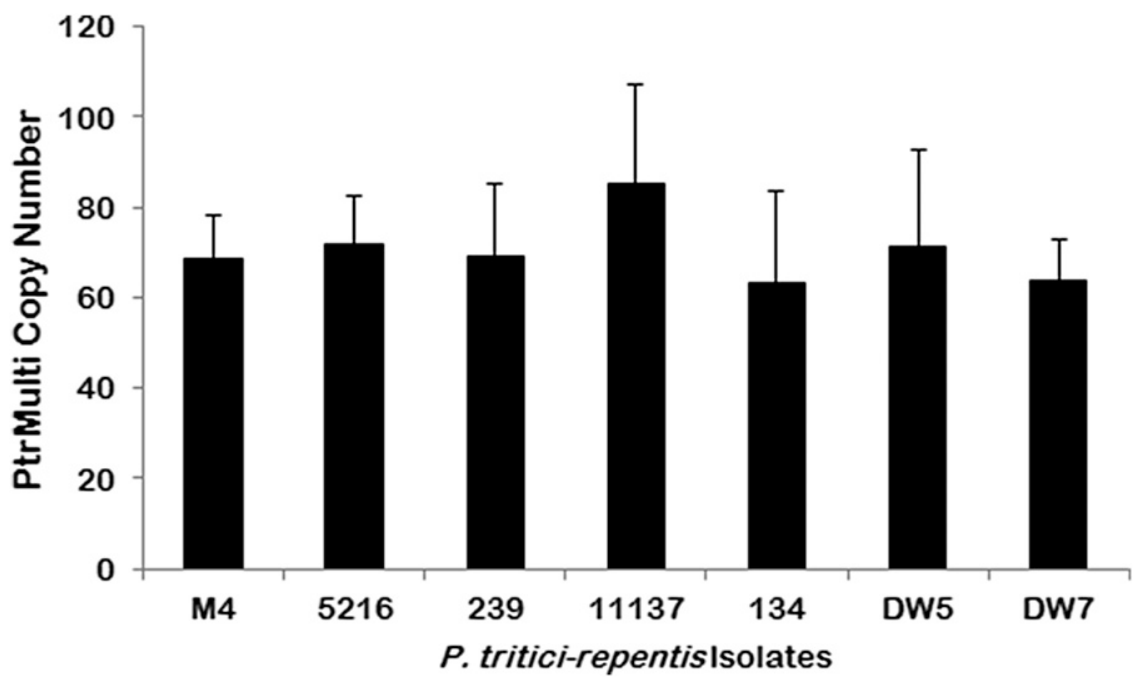

Fig. 5. Relative genome copies of PtrMulti probe in Pyrenophora tritici-repentis isolates determined by quantitative polymerase chain reaction. Each data point represents the mean and error bars represent the standard deviation. 
performing qPCR using wheat plant DNA spiked with $P$. triticirepentis DNA at the ratio of 1:10, 1:100, and 1:1,000. The qPCR analysis showed that the amplification of PtrMulti was specific, as indicated by a single melt curve (Supplementary Fig. S1). No amplification curves were detected in wheat DNA-only samples. Absolute quantification analysis using PtrMulti as the probe detected the P. tritici-repentis DNA at the expected concentration levels of 1 , 10 , and $100 \mathrm{pg}$ (Fig. 6A). In comparison with the single-locus PtrUnique, qPCR amplification detected P. tritici-repentis DNA at the levels of 10 and $100 \mathrm{pg}$. However, amplification curves were below the threshold for DNA level of $1 \mathrm{pg}$. The lower sensitivity of PtrUnique F1/R1 is shown in the regression curve generated from the serial diluted DNA with corresponding $\mathrm{Ct}$ value of 34 for DNA at $0.01 \mathrm{ng}$, whereas the equivalent DNA level of PtrMulti_F/R has a Ct value of 27 (Fig. 6B). This result confirms that PtrMulti amplification is not only species-specific but also has a higher sensitivity in comparison with a single-locus probe, which makes the PtrMulti_F/R SYBR qPCR assay a more sensitive and specific assay to detect the presence of $P$. tritici-repentis DNA in planta.

Detection of tan spot disease in naturally infected wheat. The suitability of the PtrMulti_F/R primers and qPCR assay were evaluated on tan-spot-infected Yitpi wheat. Growth stages of stem elongation (GS30), flag leaf emergence or booting (GS39 to GS40), flowering (GS60), and grain fill (GS70) were chosen for qPCR analysis to represent a cross section of wheat development phases. Specificity and sensitivity of the assay was assessed by the detection of $P$. tritici-repentis DNA on the emerged leaves of individual wheat plants from the oldest (L1) to the youngest (L6) leaves collected for a duration of 4 months, representing the different growth stages.
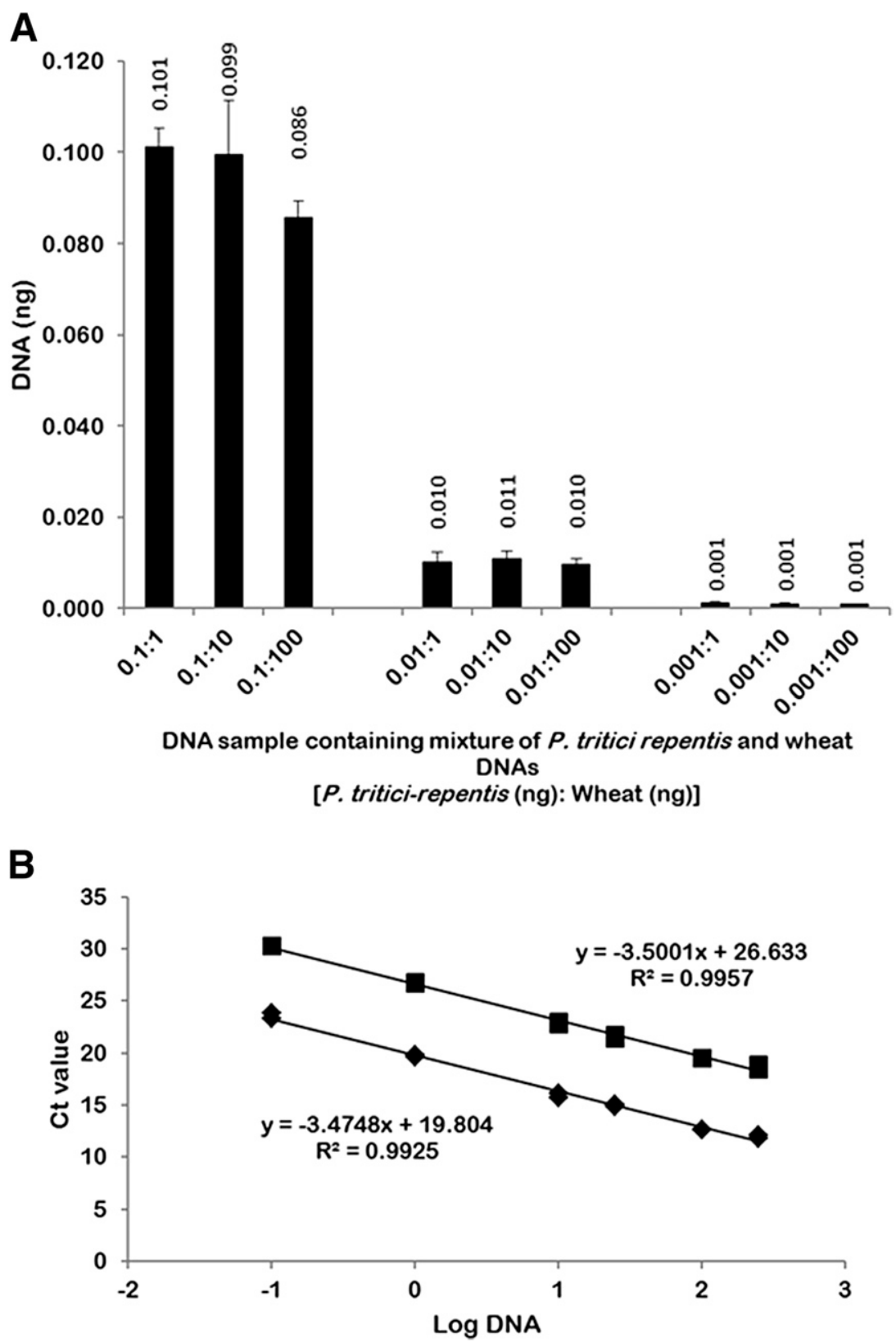

Fig. 6. A, Detection of Pyrenophora tritici-repentis DNA using primer PtrMulti_F and PtrMulti_R in a mixed DNA matrix. Wheat DNA at concentrations of 1, 10, and 100 ng were each spiked with $P$. tritici-repentis DNA at concentrations of 1,10 , and $100 \mathrm{pg}$, respectively. The amount of $P$. tritici-repentis DNA detected is shown on the plot as mean \pm standard deviation. B, Comparison of quantitative polymerase chain reaction sensitivity between multiloci PtrMulti and single-locus PtrUnique. Standard regression lines of diluted $P$. triticirepentis DNA were generated by primer pairs PtrMulti_F/R and PtrUniqueF1/R1. Threshold cycle (Ct) values are plotted against the log DNA concentrations of 250, 100, 25, 10, 1 , and $0.1 \mathrm{ng}$. The corresponding equation and $R^{2}$ value of each primer pair are shown on the plot. 
From visual inspection, this cultivar developed typical symptoms of tan spot during the growing period, with distinctive lesion of tan with chlorotic halos clearly visible on older leaves of samples collected from August onward (Fig. 7B, C, and D), whereas less symptoms were observed and no distinctive lesions were visible on the youngest leaf (L3) of the wheat samples for the first samples collected (Fig. 7A). In the qPCR assay, in general, DNA of $P$. tritici-repentis was detected in all the wheat leaf samples collected from July to October but differed in the levels of DNA concentrations (Fig. 8). In the stem elongation stage, emergence of tan spot symptoms was seen on the older leaves (L1 and L2; Fig. 7A). Although no distinct tan spot symptoms were observed on the youngest leaf (L3), qPCR analysis detected $P$. tritici-repentis DNA in all the leaves (Fig. 8). A concentration of $0.0111 \pm 0.0050 \mathrm{ng}$ was detected in L1, while a very low amount of DNA, at a concentration of $0.0006 \pm$ 0.0003 and $0.0001 \pm 5 \mathrm{E}-05 \mathrm{ng}$, was detected in L2 and L3 leaves, respectively. Although the amount of DNA detected in the older leaves was higher (100-fold) than the younger leaves, Tukey's test analysis showed no significant difference. For the next growth stage, a very high level of $P$. tritici-repentis DNA at a concentration of $4.4662 \pm 0.6882 \mathrm{ng}$ was observed in the oldest leaves (L1), which were predominantly senesced leaves. A sequential decrease in the level of DNA was observed from older L2 leaf to younger L4 leaf, with concentrations at $0.8076 \pm 0.3926,0.1281 \pm 0.0954$, and $0.0097 \pm 0.0047 \mathrm{ng}$, respectively. The fungal DNA for the following leaves (L5 and L6) remained low, at concentrations of $0.0002 \pm$ 0.0001 and $0.0009 \pm 0.0003 \mathrm{ng}$, respectively. At the flowering stage, the symptoms were less discerning in L1 and L2 leaves as the lower leaves were going through senescence (Fig. 7C). The concentration of $P$. tritici-repentis DNA was higher in the older L1 leaf in comparison with the other leaves at that stage. A half-fold of DNA level was detected in the L2 leaf, although this was not statistically significantly different from L1. The remaining L3 and L4 leaves had lower DNA levels of $0.0591 \pm 0.0247$ and $0.0015 \pm$ $0.0009 \mathrm{ng}$, respectively. For the fourth samples collected in October, the $P$. tritici-repentis DNA levels for all the leaves were consistently high within the range of a nanogram, which was reflected by the more progressed disease symptoms observed on the leaves (Fig. 7D). Leaf L1 had a DNA level of $1.1951 \pm 0.4759 \mathrm{ng}$; however, fungal DNA detected in the younger leaves (L2 and L3) was significantly higher, with a four- to sixfold increase in the levels of DNA.

Determination of photosynthetic pigments in infected wheat leaves. In the stem elongation stage, the leaves (L1, L2, and L3) had similar range of chlorophyll $a$ and $b$ content at $5.60 \pm 0.78$, $6.18 \pm 1.96$, and $3.51 \pm 0.54 \mu \mathrm{g} \mathrm{ml}^{-1}$, respectively (Fig. 9). The carotenoid content in the leaves was more than 10 -fold lower than the chlorophyll contents, ranging from $0.40 \pm 0.14$ to $0.63 \pm 0.12$ $\mu \mathrm{g} \mathrm{ml}^{-1}$. Similar to the chlorophyll contents, no significant difference in the concentration of carotenoid between the leaves was found. For the August samples, the chlorophyll content of the oldest leaf (L1) was significantly lower at $0.49 \pm 0.05 \mu \mathrm{g} \mathrm{ml}^{-1}$ in comparison with the younger leaves (L3, L4, and L5). These leaves had more than 10-fold higher measurement of chlorophyll $a$ and $b$ than L1. The other leaves (L2 and L6) had chlorophyll contents of $3.78 \pm 1.24$ and $4.48 \pm 1.24 \mu \mathrm{g} \mathrm{ml}^{-1}$, respectively, which was not statistically significantly different from L1. The distributions of the carotenoid concentrations between the leaves of different ages were similar to the chlorophyll concentrations, with a significantly lower level detected in the oldest leaf (L1) and increased carotenoid levels in the younger leaves. A very low level of carotenoid was detected in leaf L1 at concentration of $0.17 \pm$ $0.09 \mu \mathrm{g} \mathrm{ml}^{-1}$. The rest of the younger leaves had higher carotenoid concentrations, ranging from $0.70 \pm 0.23$ to $1.20 \pm 0.30 \mu \mathrm{g} \mathrm{ml}^{-1}$, with no significant difference observed between the leaves. The leaves from the September sample collection had a concentration of chlorophyll $a$ and $b$ that ranged from of $1.33 \pm 0.75$ to $5.73 \pm$ $2.52 \mu \mathrm{g} \mathrm{ml}^{-1}$. Data showed a gradual increment in the concentrations of chlorophyll $a$ and $b$ corresponding to the age of the leaves, with the highest concentration detected in L4. The carotenoid levels were not significantly different between the leaves (L1 to L4). The chlorophyll content of the leaf samples of different ages collected in October were not statistically different, with the concentrations ranging from $0.81 \pm 0.76$ to $2.9 \pm 2.02 \mu \mathrm{g} \mathrm{ml}^{-1}$. The carotenoid content of L1
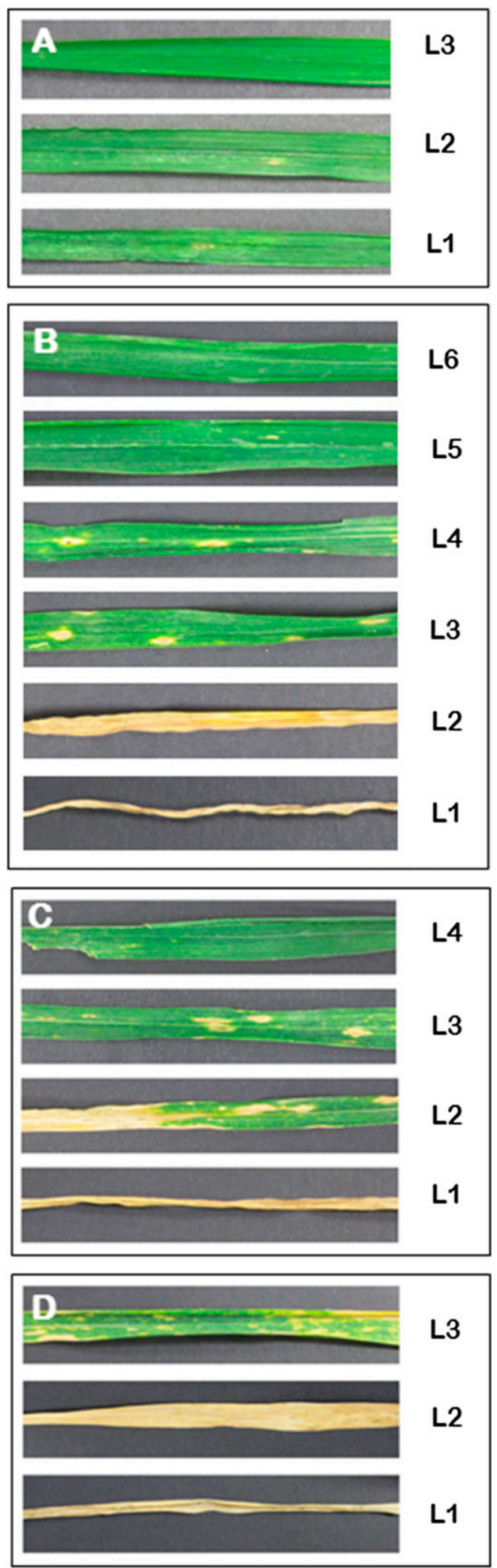

Fig. 7. Symptoms of tan spot on naturally infected wheat field samples. Disease progression throughout the wheat-growing period of A, stem elongation (GS30); $B$, flag leaf emergence or booting (GS39 to GS40); C, flowering (GS60); and D, grain fill (GS70). For each wheat plant, individual leaves were analyzed. These leaves were labeled $L 1$ to $L 6$ as indicated at the right of the figure, representing the oldest to the youngest emerged leaves. 
was $0.21 \pm 0.25 \mu \mathrm{g} \mathrm{ml}^{-1}$; however, no carotenoid was detected in L2 and L3.

\section{Discussion}

In the past, timely diagnosis of tan spot disease in wheat using conventional methods was challenging due to the reliance of agar plate fungal culturing and microscopic observation for identification. However, certain Pyrenophora spp. are not distinctly different in morphology (Zhang and Berbee 2001). For this reason, the tan spot diagnosis method requires a combination of conventional PCR using speciesspecific primers or sequencing of the ITS region in order to confirm at the species level. With the technology of fluorescent detection and the availability of genome information, the development of plant disease diagnostics has been geared toward a more robust, rapid, and specific assay for pathogen detection, with a certain degree of quantitation. A multicopy-locus probe, PtrMulti, was developed to facilitate the diagnosis of tan spot disease, and the probe proved useful in discerning tan spot symptoms from spontaneous yellowing of wheat leaves in Mace (Moffat et al. 2015). In this study, PtrMulti was shown as a multicopy locus with near-equal copies per genome for the different geographical isolates examined. In contrast to other multilocus probes that have more than twofold differences between the isolates (Herrera et al. 2009; Johnson et al. 2015; Longo et al. 2013), the lack of variation between the PtrMulti copy numbers of the different isolates makes the PtrMulti probe useful for comparative analysis of $P$. tritici-repentis loads between the diverse pathogen populations.

In order to employ PtrMulti as a routine diagnostic probe, a wider application of PtrMulti was evaluated in this study. PtrMulti not only was used as a diagnostic probe but also was assessed as a quantitation probe to determine the levels of tan spot disease on naturally infected wheat. Amplification of PtrMulti_F/R is clearly specific, with a distinct band observed only in P. tritici-repentis and not in other closely related Pleosprales members such as $P$. nodorum and Alternaria spp., which have been shown to coexist on infected tissues as complexes or opportunistic saprophytes (Bhathal et al. 2003; Moffat et al. 2015). Even though a locus in P. teres f. teres genome showed some homology to the PtrMulti probe region, further optimization of the PCR conditions (i.e., higher annealing temperature and proofreading DNA polymerase) for the PtrMulti_F/R primer pair could discern the two different pathogens. Furthermore, $P$. tritici-repentis and $P$. teres f. teres are two major pathogens on different crops and they produce very different foliar disease symptoms. If situations of mixed hosts of wheat and barley are routinely encountered, it is recommended to incorporate fluorescence-labeled probes in the middle of the amplicon such as Taqman because this may well increase the specificity to the target multiloci PtrMulti region. Interestingly, in this study, preliminary quantitative analysis of qPCR primer set Ptt_F and Ptt_R produced the amplicon from genomic DNA of $P$. teres $\mathrm{f}$. teres but not $P$. teres $\mathrm{f}$. maculata. More analyses of $P$. teres isolates are needed to evaluate the specificity of Ptt_F/R primers because, in this study, only two isolates of each $P$. teres form were examined. It is worth further investigating this locus in $P$. teres because, in this study, the primer pair Ptt_F/R appears to be $P$. teres $\mathrm{f}$. teres species specific.

The detection of the multilocus PtrMulti has a higher sensitivity in comparison with the single-locus PtrUnique. Quantification of $P$. tritici-repentis DNA using PtrMulti was feasible over three orders of magnitude (from 1 to $100 \mathrm{pg}$ ) whereas PtrUnique has a detection limit of $>1 \mathrm{pg}$. The higher sensitivity of PtrMulti amplification is seen in the standard curve, with $10 \mathrm{pg}$ detected at a $\mathrm{Ct}$ value of 27 . Based on the regression curve, the PtrMulti detection limit would be $80 \mathrm{fg}$. The detection sensitivity was demonstrated in wheat field samples with the quantification of $P$. tritici-repentis DNA in the range of fentograms mainly in the younger leaves, with less discerning tan spot symptoms leaves at the stem elongation stage. This highlighted the potential of PtrMulti to be used for the early detection of P. triticirepentis in wheat leaves without distinct tan spot symptoms. The sensitivity of PtrMulti detection is consistent with other multicopy probes used in qPCR detection of plant diseases such as those that

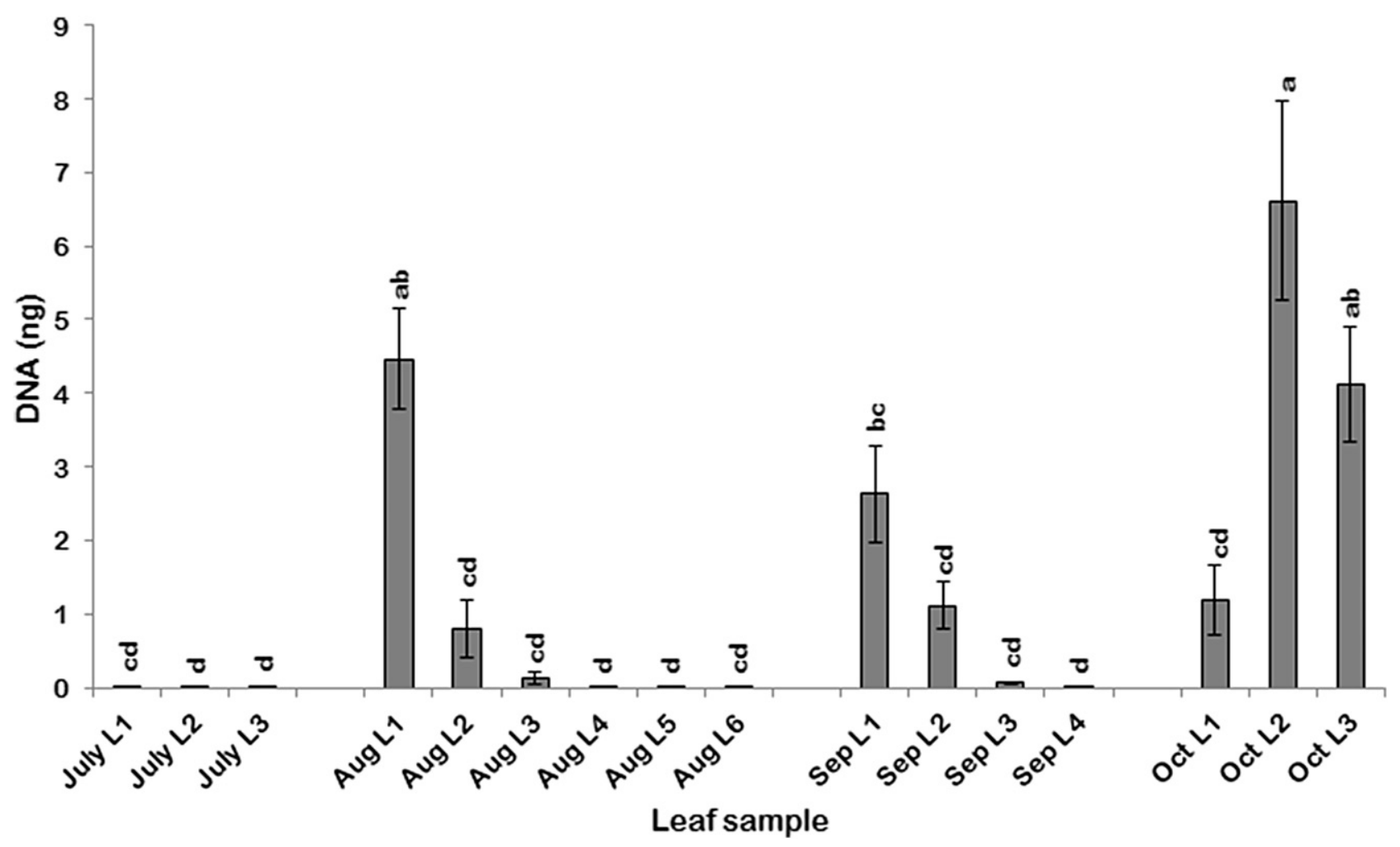

Fig. 8. Detection and quantification of Pyrenophora tritici-repentis DNA in naturally infected wheat leaves using quantitative polymerase chain reaction. Wheat leaf samples were collected at the growth stages of GS30 (July), GS39 to GS40 (August), GS60 (September), and GS70 (October), and individual leaves of each plant ranging from the oldest leaf (L1) to the youngest leaf $(\mathrm{L} 6)$ were analyzed. Data are shown as mean concentration of $P$. tritici-repentis DNA, and error bars indicates standard deviation. Different letters indicate statistically significant differences between the means according to Tukey's test $(P<0.05)$. 
employ rDNA ITS multicopy loci with the detection of pathogen DNA at fentogram levels (Arif et al. 2014; Molnar et al. 2013). A comparable detection study of the Phomopsis scleorotiodies pathogen using rDNA primers reported a lower limit detection level of $0.4 \mathrm{fg}$ for both SYBR green and Taqman probe-based real-time PCR assays, which was shown to be 100 times more sensitive than a standard PCR assay (Shishido et al. 2013). Meanwhile, the detection limit of a singlecopy probe such as the elongation factor gene usually falls in the range of $\geq 1 \mathrm{pg}$ (Amatulli et al. 2012; Haegi et al. 2013), as shown in the detection limit of the single-locus PtrUnique in this study.

A concern with most qPCR detection methods is the inability of the assay to discern whether the quantified DNA is from viable fungal materials or dead cells. Although, in this study, the viability of the fungal load present in the infected leaves was not assayed, the levels of $P$. tritici-repentis DNA detected corresponded with the visual assessment of the foliar disease. Numerous studies have investigated the correlation of positive quantification of PCR with the detection of fungal propagules in the infected tissues, and have found significant correlations. Significant correlation has been demonstrated between quantification of pathogen DNA using a qPCR method with conventional agar plate culture in the studies of Sclerotinia sclerotiorum infection of oilseed red petals (Almquist and Wallenhammar 2015) and $P$. teres seed infection (Bates et al. 2001). Intriguingly, a qPCR assay supported the observation of different degrees of $F$. oxysporum $\mathrm{f}$. sp. melonis colonization on melon stem between compatible and incompatible interactions, with higher fungal DNA detected in compatible interactions (Haegi et al. 2013). These studies demonstrated that levels of DNA correlate with the degree of pathogenicity, thus supporting the application of PtrMulti as a probe for quantitative diagnostic.

The qPCR data in this study generally showed that younger leaves have less $P$. tritici-repentis DNA, and a higher incidence of infection was observed in older leaves, indicated by a higher concentration of the DNA. A higher incidence of pathogens in lower leaves was also reported for S. sclerotiorium (Almquist and Wallenhammar 2015). There are several reasons that have been suggested for this occurrence; lower leaves are exposed longer to airborne spores, are closer to the ground, have a larger surface area, and are more senescent. Despite varying degrees of infection observed at the stem elongation and ear emergence stages, at the last sampling date, all the flag leaves tested had high levels of $P$. tritici-repentis DNA. This high incidence of tan spot disease indicates a continual progression of disease development throughout the various growth stages examined in this study. This observation is of a particular disease progression of tan spot infection, with infection mostly occurring in older leaves (Summerell and Burgess 1988). This study shows that, even though $P$. tritici-repentis DNA was detected at a lower concentration at the earlier growth stage and on younger leaves, at the later stage, the tan spot disease can progress and continue to intensify, producing large chlorotic and necrotic lesions and, consequently, decreasing the photosynthetic pigments of the leaves. This is perhaps influenced by conditions such as rainfall during the growing season that promote the development of disease. The lack of disease suppression in this study is likely caused by the susceptibility of the cultivar that was selected. At the maturation stage, the foliar structure also goes through senescence, with a reduction of photosynthetic pigment content in the leaf samples of the fourth sampling stage. Tan spot disease continues to progress as the pathogen enters the saprophytic phase of development and colonizes the senescent leaf and leaf sheath. Higher concentrations of $P$. tritici-repentis DNA appear to occur on leaf samples with lower contents of photosynthetic pigments, supporting the visual observation by Summerell and Burgess (1988) that leaf senescence stimulates $P$. tritici-repentis host colonization.

To our knowledge, this is the first report of using molecular diagnostics for tan spot disease in the field. The multicopy-locus PtrMulti_F/R SYBR green qPCR assay was reliable in the detection and quantification of $P$. tritici-repentis on wheat leaves of naturally infected field samples. The sensitivity of the diagnostic assay has an advantage in the early detection of tan spot disease and as a useful tool for managing application of fungicide. Such application also has practical implications as a quantitative tool to study the epidemiology of the tan spot pathogen in the field and aid in the determination of high-risk areas. Furthermore, the PtrMulti SYBR green PCR assay is relatively inexpensive in comparison with other fluorescence technology for large-scale, routine monitoring of tan spot disease or rapid screening of germplasm for enhanced resistance.

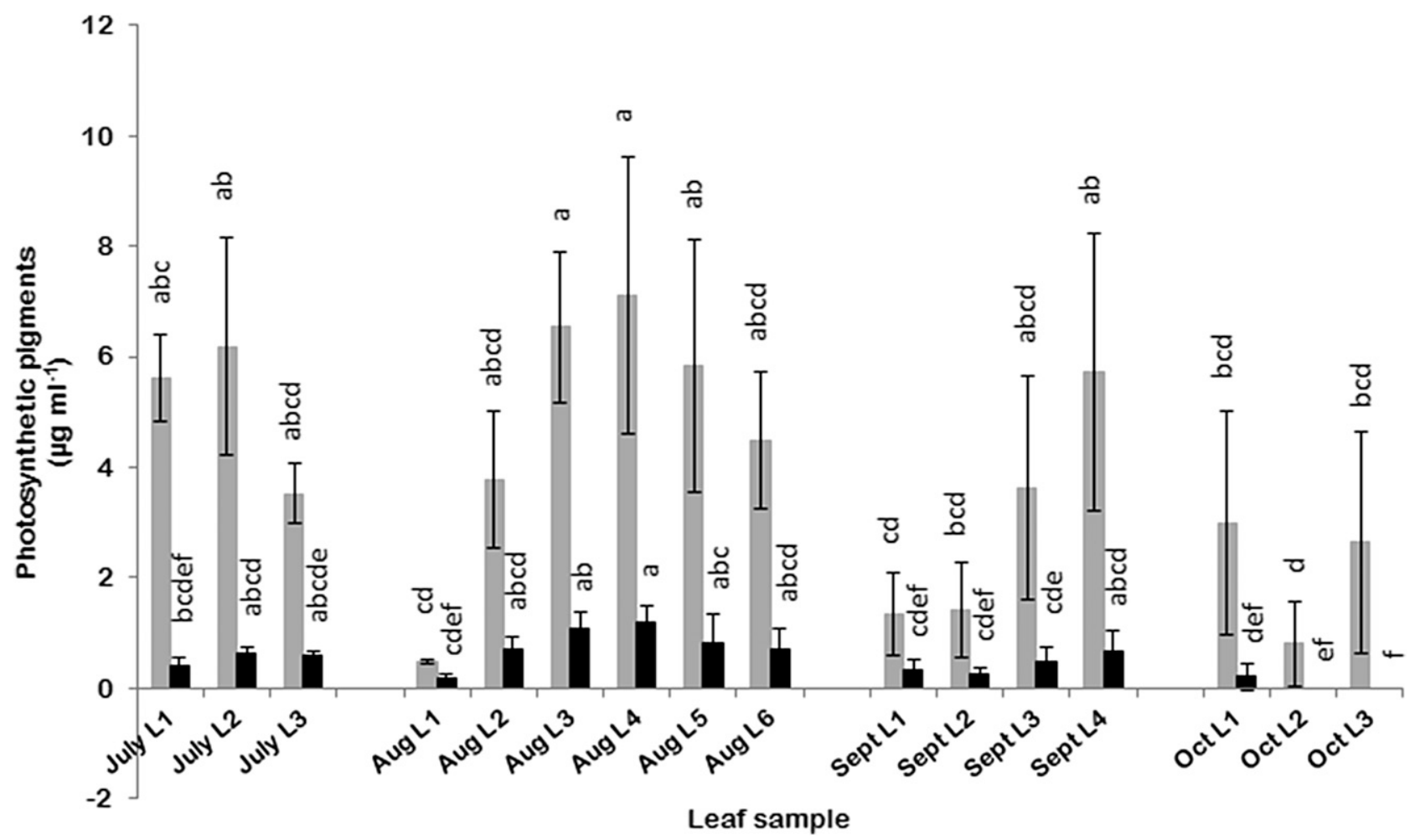

Fig. 9. Quantification of photosynthetic pigments concentration in the wheat leaf samples. Measurements of chlorophyll $a$ and $b$, and carotenoid are shown as gray and black bars, respectively. Mean values with different letters differ significantly $(P<0.05)$ according to Tukey's test. 


\section{Acknowledgments}

This work was supported by grants from the Australian Grains Research and Development Corporation. We thank T. Friesen (United States Department of Agriculture-Agricultural Research Service) for the U.S. P. tritici-repentis isolates; the research staff at the Centre for Crop and Disease Management, Curtin University, for providing DNA of P. nodorum, Ascochyta spp., and B. cinerea; the Department of Agriculture and Food Western Australia and Queensland Department of Agriculture and Fisheries for providing the Australian isolates; and S. Ellwood (Curtin University) for his technical assistance.

\section{Literature Cited}

Aboukhaddour, R., Turkington, T. K., and Strelkov, S. E. 2013. Race structure of Pyrenophora tritici-repentis (tan spot of wheat) in Alberta, Canada. Can. J. Plant Pathol. 35:256-268.

Ali, S., and Francl, L. J. 2002. A new race of Pyrenophora tritici-repentis from Brazil. Plant Dis. 86:1050.

Ali, S., Gurung, S., and Adhikari, T. B. 2010. Identification and characterization of novel isolates of Pyrenophora tritici-repentis from Arkansas. Plant Dis. 94: 229-235.

Almquist, C., and Wallenhammar, A. C. 2015. Monitoring of plant and airborne inoculum of Sclerotinia sclerotiorum in spring oilseed rape using real-time PCR. Plant Pathol. 64:109-118.

Amatulli, M. T., Spadaro, D., Gullino, M. L., and Garibaldi, A. 2012. Conventional and real-time PCR for the identification of Fusarium fujikuroi and Fusarium proliferatum from diseased rice tissues and seeds. Eur. J. Plant Pathol. 134:401-408.

Andrie, R. A., Pandelova, L., and Ciuffetti, L. A. 2007. A combination of phenotypic and genotypic characterization strengthens Pyrenophora triticirepentis race identification. Phytopathology 97:694-701.

Antoni, E. A., Rybak, K., Tucker, M. P., Hane, J. K., Solomon, P. S., Drenth, A., Shankar, M., and Oliver, R. P. 2010. Ubiquity of ToxA and absence of ToxB in Australian populations of Pyrenophora tritici-repentis. Australas. Plant Pathol. 39:63-68.

Arif, M., Dobhal, S., Garrido, P. A., Orquera, G. K., Espindola, A. S., Young, C. A., Ochoa-Corona, F. M., Marek, S. M., and Garzon, C. D. 2014. Highly sensitive end-point PCR and SYBR green qPCR detection of Phymatotrichopsis omnivora, causal fungus of cotton root rot. Plant Dis. 98:1205-1212.

Bates, J. A., Taylor, E. J. A., Kenyon, D. M., and Thomas, J. E. 2001. The application of real-time PCR to the identification, detection and quantification of Pyrenophora species in barley seed. Mol. Plant Pathol. 2:49-57.

Begerow, D., Nilsson, H., Unterseher, M., and Maier, W. 2010. Current state and perspectives of fungal DNA barcoding and rapid identification procedures. Appl. Microbiol. Biotechnol. 87:99-108.

Bhathal, J. S., Loughman, R., and Speijers, J. 2003. Yield reduction in wheat in relation to leaf disease from yellow (tan) spot and Septoria nodorum blotch. Eur. J. Plant Pathol. 109:435-443.

DAFWA. 2015. Wheat variety guide for Western Australia. Online publication. Department of Agriculture and Food Western Australia. https://grdc.com.au/ WAWheatVarietyGuide2015

Dorn-In, S., Bassitta, R., Schwaiger, K., Bauer, J., and Hölzel, C. S. 2015. Specific amplification of bacterial DNA by optimized so-called universal bacterial primers in samples rich of plant DNA. J. Microbiol. Methods 113:50-56.

Dreaden, T. J., Davis, J. M., Harmon, C. L., Ploetz, R. C., Palmateer, A. J., Soltis, P. S., and Smith, J. A. 2014. Development of multilocus PCR assays for Raffaelea lauricola, causal agent of laurel wilt disease. Plant Dis. 98:379-383

Egger, K. N. 1995. Molecular analysis of ectomycorrhizal fungal communities. Can. J. Bot. 73:1415-1422.

Elder, J. F., Jr., and Turner, B. J. 1995. Concerted evolution of repetitive DNA sequences in eukaryotes. Q. Rev. Biol. 70:297-320.

Ellwood, S. R., Syme, R. A., Moffat, C. S., and Oliver, R. P. 2012. Evolution of three Pyrenophora cereal pathogens: Recent divergence, speciation and evolution of non-coding DNA. Fungal Genet. Biol. 49:825-829.

Fernandez, M. R., DePauw, R. M., Clarke, J. M., and Fox, S. L. 1998. Discoloration of wheat kernels by Pyrenophora tritici-repentis. Can. J. Plant Pathol. Rev. Can. Phytopathol. 20:380-383.

Friesen, T. L., and Faris, J. D. 2004. Molecular mapping of resistance to Pyrenophora tritici-repentis race 5 and sensitivity to Ptr ToxB in wheat. Theor. Appl. Genet. 109:464-471.

Friesen, T. L., Stukenbrock, E. H., Liu, Z., Meinhardt, S., Ling, H., Faris, J. D., Rasmussen, J. B., Solomon, P. S., McDonald, B. A., and Oliver, R. P. 2006. Emergence of a new disease as a result of interspecific virulence gene transfer. Nat. Genet. 38:953-956.

Gamba, F. M., Strelkov, S. E., and Lamari, L. 2012. Virulence of Pyrenophora tritici-repentis in the Southern Cone Region of South America. Can. J. Plant Pathol. 34:545-550.

Gardes, M., and Bruns, T. D. 1993. ITS primers with enhanced specificity for basidiomycetes - application to the identification of mycorrhizae and rusts. Mol. Ecol. 2:113-118.

Haegi, A., Catalano, V., Luongo, L., Vitale, S., Scotton, M., Ficcadenti, N., and Belisario, A. 2013. A newly developed real-time PCR assay for detection and quantification of Fusarium oxysporum and its use in compatible and incompatible interactions with grafted melon genotypes. Phytopathology 103:802-810.
Herrera, M. L., Vallor, A. C., Gelfond, J. A., Patterson, T. F., and Wickes, B. L. 2009. Strain-dependent variation in 18 S ribosomal DNA copy numbers in Aspergillus fumigatus. J. Clin. Microbiol. 47:1325-1332.

Ihrmark, K., Bodeker, I. T., Cruz-Martinez, K., Friberg, H., Kubartova, A., Schenck, J., Strid, Y., Stenlid, J., Brandstrom-Durling, M., Clemmensen, K. E., and Lindahl, B. D. 2012. New primers to amplify the fungal ITS2 region-evaluation by 454-sequencing of artificial and natural communities. FEMS Microbiol. Ecol. 82:666-677.

Jiménez-Fernández, D., Montes-Borrego, M., Jimenez-Diaz, R. M., Navas-Cortes, J. A., and Landa, B. B. 2011. In planta and soil quantification of Fusarium oxysporum f. sp. ciceris and evaluation of Fusarium wilt resistance in chickpea with a newly developed quantitative polymerase chain reaction assay. Phytopathology 101:250-262.

Johnson, S., Carlson, E., and Pappagianis, D. 2015. Determination of ribosomal DNA copy number and comparison among strains of Coccidioides. Mycopathologia 179:45-51.

Kenny, P., Deák, Z., Csôsz, M., Purnhauser, L., and Vass, I. 2011. characterization and early detection of tan spot disease in wheat in vivo with chlorophyll fluorescence imaging. Acta Biol. Szeged. 55:87-90.

Lamari, L., Sayoud, R., Boulif, M., and Bernier, C. C. 1995. Identification of a new race in Pyrenophora tritici-repentis: Implications for the curren pathotype classification system. Can. J. Plant Pathol. Rev. Can. Phytopathol 17:312-318.

Lamari, L., Strelkov, S. E., Yahyaoui, A., Orabi, J., and Smith, R. B. 2003. The identification of two new races of Pyrenophora tritici-repentis from the host center of diversity confirms a one-to-one relationship in tan spot of wheat. Phytopathology 93:391-396.

Lepoint, P., Renard, M. E., Legreve, A., Duveiller, E., and Maraite, H. 2010. Genetic diversity of the mating type and toxin production genes in Pyrenophora triticirepentis. Phytopathology 100:474-483.

Lichtenthaler, H. K., and Wellburn, A. R. 1983. Determinations of total carotenoids and chlorophylls $a$ and $b$ of leaf extracts in different solvents. Biochem. Soc. Trans. 11:591-592.

Lindner, D. L., and Banik, M. T. 2011. Intragenomic variation in the ITS rDNA region obscures phylogenetic relationships and inflates estimates of operational taxonomic units in genus Laetiporus. Mycologia 103:731-740.

Lindner, D. L., Carlsen, T., Henrik Nilsson, R., Davey, M., Schumacher, T., and Kauserud, H. 2013. Employing 454 amplicon pyrosequencing to reveal intragenomic divergence in the internal transcribed spacer rDNA region in fungi. Ecol. Evol. 3:1751-1764.

Longo, A. V., Rodriguez, D., da Silva Leite, D., Toledo, L. F., Mendoza Almeralla, C. Burrowes, P. A., and Zamudio, K. R. 2013. Correction: ITS1 copy number varies among Batrachochytrium dendrobatidis strains: Implications for $\mathrm{qPCR}$ estimates of infection intensity from field-collected amphibian skin swabs. PLoS One 8(10). doi:10.1371/annotation/e4c527e6-4b6f-4c12-970c-a9e2e6ed8f79

Manning, V. A., Pandelova, I., Dhillon, B., Wilhelm, L. J., Goodwin, S. B., Berlin, A. M., Figueroa, M., Freitag, M., Hane, J. K., Henrissat, B., Holman, W. H., Kodira, C. D., Martin, J., Oliver, R. P., Robbertse, B., Schackwitz, W., Schwartz, D. C., Spatafora, J. W., Turgeon, B. G., Yandava, C., Young, S., Zhou, S., Zeng, Q., Grigoriev, I. V., Ma, L.-J., and Ciuffetti, L. M. 2013. Comparative genomics of a plant-pathogenic fungus, Pyrenophora triticirepentis, reveals transduplication and the impact of repeat elements on pathogenicity and population divergence. G3: Genes Genomes Genet. 3:41-63.

Martin, K., and Rygiewicz, P. 2005. Fungal-specific PCR primers developed for analysis of the ITS region of environmental DNA extracts. BMC Microbiol. 5:28.

Moffat, C. S., See, P. T., and Oliver, R. P. 2014. Generation of a ToxA knockout strain of the wheat tan spot pathogen Pyrenophora tritici-repentis. Mol. Plant Pathol. 15:918-926.

Moffat, C. S., See, P. T., and Oliver, R. P. 2015. Leaf yellowing of the wheat cultivar Mace in the absence of yellow spot disease. Australas. Plant Pathol. 44:161-166.

Molnar, T. J., Walsh, E., Capik, J. M., Sathuvalli, V., Mehlenbacher, S. A., Rossman, A. Y., and Zhang, N. 2013. A real-time PCR assay for early detection of eastern filbert blight. Plant Dis. 97:813-818.

Monard, C., Gantner, S., and Stenlid, J. 2013. Utilizing ITS1 and ITS2 to study environmental fungal diversity using pyrosequencing. FEMS Microbiol. Ecol. 84:165-175.

Murray, G. M., and Brennan, J. P. 2009. Estimating disease losses to the Australian wheat industry. Australas. Plant Pathol. 38:558-570.

Mutka, A., and Bart, R. 2015. Image-based phenotyping of plant disease symptoms. Front. Plant Sci. 5. doi:10.3389/fpls.2014.00734

O'Brien, H. E., Parrent, J. L., Jackson, J. A., Moncalvo, J. M., and Vilgalys, R. 2005. Fungal community analysis by large-scale sequencing of environmental samples. Appl. Environ. Microbiol. 71:5544-5550.

Oliver, R. P., Lord, A., Rybak, K., Faris, J. D., and Solomon, P. S. 2008 Emergence of tan spot disease caused by toxigenic Pyrenophora triticirepentis in Australia is not associated with increased deployment of toxinsensitive cultivars. Phytopathology 98:488-491.

Sanzani, S. M., Nicosia, M., Faedda, R., Cacciola, S. O., and Schena, L. 2014. Use of quantitative PCR detection methods to study biocontrol agents and phytopathogenic fungi and oomycetes in environmental samples. J. Phytopathol. 162:1-13. 
Schoch, C. L., Seifert, K. A., Huhndorf, S., Robert, V., Spouge, J. L., Levesque, C. A., Chen, W., and Consortium, F. B. 2012. Nuclear ribosomal internal transcribed spacer (ITS) region as a universal DNA barcode marker for fungi. Proc. Natl. Acad. Sci. USA 109:6241-6246.

Shishido, M., Kubota, I., Ohashi, T., and Usami, T. 2013. Comparison of PCR assays for detection and quantification of Phomopsis sclerotioides in plant and soil. J. Gen. Plant Pathol. 79:18-27.

Summerell, B. A., and Burgess, L. W. 1988. Saprophytic colonization of wheat and barley by Pyrenophora tritici-repentis in the field. Trans. Br. Mycol. Soc. 90:551-556.
Whelan, J. A., Russell, N. B., and Whelan, M. A. 2003. A method for the absolute quantification of cDNA using real-time PCR. J. Immunol. Methods 278: 261-269.

White, T. J., Bruns, T., Lee, S., and Taylor, J. 1990. Amplification and direct sequencing of fungal ribosomal RNA genes for phylogenetics. Pages 315-322 in: PCR Protocols: A Guide to Methods and Applications. M. A. Innis, D. H. Gefand, J. J. Sninsky, and T. J. White, eds. Academic Press, San Diego.

Zhang, G., and Berbee, M. L. 2001. Pyrenophora phylogenetics inferred from ITS and glyceradehyde-3-phosphate dehydrogenase gene sequences. Mycologia 93: 1048-1063. 